TITLE:

\title{
pH-responsive non-surface- active/surface-active transition of weakly ionic amphiphilic diblock copolymers
}

AUTHOR(S):

Matsuoka, Hideki; Onishi, Tomoyuki; Ghosh, Arjun

\section{CITATION:}

Matsuoka, Hideki ... [et al]. pH-responsive non-surface-active/surface-active transition of weakly ionic amphiphilic diblock copolymers. Colloid and Polymer Science 2013, 292(4): 797-806

\section{ISSUE DATE:}

2013-11-28

URL:

http://hdl.handle.net/2433/198680

\section{RIGHT:}

The final publication is available at Springer via http://dx.doi.org/10.1007/s00396-0133125-4.; この論文は出版社版でありません。引用の際には出版社版をご確認ご利用くだ さい。; This is not the published version. Please cite only the published version. 


\section{pH-Responsive Non-Surface Active / Surface Active Transition of Weakly Ionic Amphiphilic Diblock Copolymers}

Hideki Matsuoka*, Tomoyuki Onishi, and Arjun Ghosh

Department of Polymer Chemistry, Kyoto University, Kyoto 615-8510, Japan

* To whom correspondence should be addressed.

e-mail: matsuoka.hideki.3s@kyoto-u.ac.jp 


\section{Abstract}

The weakly ionic amphiphilic diblock copolymer polystyrene- $b$-poly(acrylic acid), was synthesized by nitroxy radical mediated living radical polymerization with precise control of block length, block ratio, and polydispersity. Systematical surface tension experiments and foam formation observations revealed that this polymer was non-surface-active under neutral and alkaline ( $\mathrm{pH} \mathrm{10)} \mathrm{conditions,} \mathrm{while} \mathrm{it} \mathrm{was} \mathrm{surface-active}$ under an acidic condition ( $\mathrm{pH} 3$ ). This result supports our proposed origin of non-surface activity; the image charge repulsion at the air/water interface is essential in addition to very stable micelle formation in the bulk solution. At a higher $\mathrm{pH}(\mathrm{pH} 12)$, the polymer showed slight surface activity since the added $\mathrm{NaOH}$ played a role as an added salt. The critical micelle concentration (cmc) was estimated by static light scattering. Cmc increased with increasing added salt $(\mathrm{NaCl})$ concentration as was observed for other strongly ionic non-surface active polymers. Hence, this trend is characteristic for non-surface active polymers. The $\mathrm{pH}$ dependence of $\mathrm{cmc}$ was minimum at $\mathrm{pH} 8$ - 10. Since the acrylic acid block is fully ionized under this condition, the strong image charge repulsion at this condition accelerated micelle formation at a low polymer concentration, which consequently decreased cmc. Micelles in bulk solution were confirmed by dynamic light scattering, and the salt concentration and $\mathrm{pH}$ dependencies of the hydrodynamic radius of the micelles were also estimated. The $\mathrm{pH}$ responsive non-surface active / surface active transition observed in this study, strongly supports the fact that the image charge repulsion is an essential factor for non-surface activity in addition to stable micelle formation in solution. 


\section{Introduction}

Various ionic amphiphilic diblock copolymers including strongly anionic [1-6], weakly anionic[7], and also cationic[8,9] polymers show a non-surface active nature. We have systematically investigated this unique, somewhat out of common sense of surface and interface science, property, and proposed that the essential origin of non-surface activity is strong image charge repulsion[10-14] at the air/water interface[2,3,5,6,9]. Very stable micelle formation in the bulk solution may also be the principal origin[ $[5,6]$ considering the fact that polyelectrolyte homopolymers are slightly surface active. Poly(styrene sulfonate) (PSS) homopolymer[15-18] and, recently, the random copolymer[6] of styrene and styrene sulfonate was found to be surface active, stressing the importance of micelle formation[5,6]. Before our study, there were already reports that the solutions of ionic amphiphilic block copolymers show no reduction of surface tension[19-24], and also reports of new non-surface active systems[25-35]. It is noteworthy that similar behavior has been found also for biological system[36]. In addition, theoretical consideration was proposed for anomalous salt concentration dependence of the critical micelle concentration of non-surface active polymers[37]. Hence, non-surface activity seems to be a universal characteristic of ionic amphiphilic diblock copolymers when some requirements are satisfied.

Requirements for molecular structure are block ratio and total length. In our systematical study, the polymers with a block ratio of around 1:1 (e.g., $m: n=50: 50, m$ and $n$ are the degree of polymerization of hydrophobic and hydrophilic blocks, respectively) showed stronger non-surface nature. When the hydrophobic block is much longer than the hydrophilic, ionic block, the polymer showed surface active nature since hydrophobic adsorption at the air/water interface is superior to the image charge repulsion[3,5,6]. When the hydrophobic 
block is much shorter than the ionic block, the polymer also shows surface activity since they can not form a stable micelle in the bulk solution[38]. The adsorbed state at the air/water interface is more stable than the molecularly dissolved unimer state in solution. In addition, $m: n=50: 50$ polymer was found to be non-surface active while $m: n=20: 20$ polymer was surface active[5]. This observation was also related to the stability of micelle, and this might be a demarcation between amphiphilic polymer and low molecular weight surfactant from the viewpoint of surface and interface chemistry, at least of non-surface activity. Requirement for an external factor is ionic strength of the solution. All the non-surface active polymers showed non-surface activity in the absence of added salt, but they became surface active after salt addition. This observation strongly suggests that the image charge repulsion is an essential factor.

In this study, as the second-step investigation of non-surface active polymers, we tried to control the non-surface active nature using external stimuli. We synthesized a weakly ionic amphiphilic diblock copolymer, poly(styrene)- $b$-poly(acrylic acid) (PSt- $b$-PAA) by nitroxy radical mediated living radical polymerization. A weakly ionic amphiphilic diblock copolymer was found to be non-surface active when neutralized[7]. However, this polymer should be surface active under acidic conditions since carboxyl groups are protonated, i.e., non-ionic, if our interpretation of non-surface activity is correct. Hence, the $\mathrm{pH}$ control of surface active / non-surface active transition should be feasible by utilizing this polymer.

\section{Experimental}

\section{Materials}

Styrene (St), $t$-butylacrylate (t-BuAc) and azobisisobuthylonitrile (AIBN, initiator) 
were purchased from Wako Chemical (Osaka, Japan). Styrene was treated with $1 \mathrm{M} \mathrm{NaOH}$ to remove the polymerization inhibitor three times. Then, moisture was removed using a $\mathrm{Na}_{2} \mathrm{SO}_{4}$ column. Calcium hydride was added and distilled twice before use. $t$-BuAc was treated in the same way. The mediator, n-t-butyl-1-diethylphosphone-2,2-dimethylpropyl nitroxy radical (DEPN), was synthesized as reported previously[2,39].

\section{Polymer synthesis}

The polystyrene homopolymer as the macroinitiator was synthesized as follows. 300:1:2.5 mixture (molar ratio) of St, AIBN, DEPN was put into a Schlenk tube, then tetrahydrofuran (THF) was added. The solution was freeze-pump-thawed under $\mathrm{Ar}$ atmosphere three times. Then, the polymerization reaction proceeded at $120^{\circ} \mathrm{C}$ typically for 68 min. The reaction was stopped by cooling in ice-water, and the THF solvent was evaporated. The conversion was estimated by ${ }^{1} \mathrm{H}$ NMR. The resultant polymer was dissolved in a small amount of THF, and re-precipitated by methanol two times. The polymer was dried again under vacuum.

The block copolymer, $\mathrm{P}(\mathrm{St})-b-\mathrm{P}(t$-BuAc) was typically synthesized as follows. 1:100:1.25 mixture (molar ratio) of PSt, t-BuAc and DEPN was put into a Schlenk tube. After three cycles of freeze-pump-thaw treatment, the polymerization reaction was allowed to proceed under an $\mathrm{Ar}$ atmosphere at $120^{\circ} \mathrm{C}$ for 3 hours. The reaction was stopped by cooling in ice-water and a small amount of THF was added to reduce the viscosity of the product. The polymer was re-precipitated two times in a methanol:water (1:1) mixture with ice cooling. The block copolymer thus obtained was dried in a vacuum chamber.

The block copolymer obtained above was hydrolyzed to obtain the aimed diblock 
copolymer, PSt- $b$-PAA as follows. PSt- $b$-P $(t-\mathrm{BuAc})$ was dissolved in 1,4-dioxane $(20 \mathrm{ml})$ in three-necked, round bottom flask at $40-50^{\circ} \mathrm{C}$ with stirring. $35 \mathrm{wt} \% \mathrm{HCl}$ aq was added $(1 \mathrm{ml}$ for $0.1 \mathrm{~g}$ polymer) and refluxed at $80^{\circ} \mathrm{C}$ for five days. The resultant polymer was purified by dialysis, and then lyophilized. The reaction scheme of this polymer synthesis is shown in Scheme 1

\section{GPC}

GPC for evaluation of molecular weight and the distribution of its PSt homopolymer and block copolymer before hydrolysis was performed by the JASCO (Tokyo, Japan) system consisting of a Shodex KF804L column, a RI-965 refractive index detector, a UV2075 Plus UV detector, a PU0980 pump, and a CO-965 column oven. Tetrahydrofuran (THF) was used as the eluent. Calibration was done using standard polystyrene.

NMR

${ }^{1} \mathrm{H}$ NMR spectra of polymers and intermediate compounds were measured by GSX -270 and AL-400 of JEOL (Tokyo, Japan).

\section{Surface tension experiment}

The surface tension of aqueous solutions was measured by the Wilhelmy method with a Face CBVP-Z surface tensiotometer (Kyowa Interface Science, Saitama, Japan). The sample solutions were prepared by dilution of the mother stock solution, and were kept overnight without disturbance before measurement. 


\section{Static light scattering (SLS)}

The critical micelle concentration (cmc) was determined by SLS. SLS instrument was Photal SLS-7000 System of Otsuka Electric Co. (Osaka, Japan). The scattering angle was fixed at $90^{\circ}$. The ratio of scattering intensity and the direct beam intensity was plotted against polymer concentration. Cmc values were evaluated from the bending point of the plot.

\section{Dynamic light scattering (DLS)}

The hydrodynamic radius $\left(R_{\mathrm{h}}\right)$ of micelle in solution was estimated using the Otsuka System equipped with a GC-1000 photon correlator. The time correlation function of the scattered field was measured at four scattering angles $\left(60^{\circ}, 75^{\circ}, 90^{\circ}\right.$, and $\left.105^{\circ}\right)$ with an accumulation time of $30 \mathrm{~min}$. The function was fitted by double exponential function according to our previous studies to estimate the decay rate $\Gamma . \quad \Gamma$ was plotted against $q^{2}$, from whose slope the translational diffusion coefficient was evaluated and changed to $R_{\mathrm{h}}$ by applying the Stokes-Einstein equation. The details were as fully described previously[2,3,40,41].

\section{Atomic force microscopy (AFM)}

Micelle formation and size were also confirmed by AFM observation using an SPI3800 system with an SPA300 probe (Seiko Instruments, Tokyo, Japan). The polymer solution $(>\mathrm{cmc})$ was dropped on a cleaned glass plate and dried in a draft chamber for observation. The non-contact mode (equivalent to "tapping" mode) was employed. 


\section{Results and Discussion}

\section{Polymer synthesis}

Figure 1 shows the ${ }^{1} \mathrm{H}$ NMR spectra for PSt homopolymer, and block copolymers before and after hydrolysis. The proton peak attributed to $t$-Bu unit disappeared after hydrolysis. Figure 2 shows GPC charts of PSt homopolymer and block copolymer before hydrolysis. The peak shifted towards a higher molecular weight, which means that we successfully obtained a PSt- $b$-PAA block copolymer together with the ${ }^{1} \mathrm{H}$ NMR experiment. In the ${ }^{1} \mathrm{H}$ NMR spectra for the final block copolymer in $\mathrm{CDCl}_{3}$, the proton peaks for the benzene unit of the PSt unit were observed, while those in $\mathrm{D}_{2} \mathrm{O}$ were not. This observation is reminiscent of the micelle formation in the heavy water, which guarantees block copolymer formation and its amphiphilic nature. The molecular characteristics of block copolymers thus obtained are summarized in Table 1. The degree of hydrolysis estimated by $\mathrm{pH}$ and conductometric titration is also shown in the table.

Table 1. Molecular characteristics of block copolymers

\begin{tabular}{lccc}
\hline Polymer & Degree of Hydrolysis & Mn & Mw/Mn \\
\hline $\mathrm{St}_{50}-b-\mathrm{AA}_{51}$ & 0.92 & 9500 & 1.33 \\
$\mathrm{St}_{27}-b-\mathrm{AA}_{51}$ & 0.77 & 7500 & 1.32 \\
$\mathrm{St}_{58}-b-\mathrm{AA}_{142}$ & 0.64 & 19000 & 1.28 \\
$\mathrm{St}_{44}-b-\mathrm{AA}_{92}$ & 0.84 & 12000 & 1.34 \\
\hline
\end{tabular}

\section{Foam Formation Observation}


The foam formation behavior of polymer solutions after vigorous hand shaking was recorded using a digital camera. Figure 3 shows the result for $\mathrm{St}_{44}-b-\mathrm{AA}_{92}$ with and without addition of $\mathrm{NaCl}$. In pure water, the solution shows little foam formation, indicating the non-surface active nature of the block copolymer. However, after $0.1 \mathrm{M} \mathrm{NaCl}$ addition, the solution showed very good foam formation, which means that the polymer became surface active. This salt effect was observed for all non-surface active polymers ever studied[1-9] and means that the non-surface activity is electrostatic in origin, probably due to the image charge repulsion at the air/water interface. As shown in Figure $4 \mathrm{St}_{50}-b-\mathrm{AA}_{51}$ and $\mathrm{St}_{27}-b-\mathrm{AA}_{51}$ showed little if any foam formation under a neutral $\mathrm{pH}$ condition, i.e., pure water, $\mathrm{pH} 8$ and pH10. Especially, the non-surface activity appears strongest at $\mathrm{pH} 10$. However, at $\mathrm{pH} 3$, both polymers showed good foam formation, indicating that the polymers are surface active under an acidic condition, where carboxylic acid of AA block is protonated, i.e., almost no charge. This observation certifies that the PSt- $b$-PAA block copolymer shows non-surface active / surface active transition by $\mathrm{pH}$ change. In Fig.5, the polymer showed slight foam formation at $\mathrm{pH}$ 12. This might be an effect of salt. To change $\mathrm{pH}, \mathrm{NaOH}$ aq. was added to the solution. Since $\mathrm{pH} 12$ is an overneutralized condition, the excess $\mathrm{NaOH}$ acts as a salt, and behavior similar to that in Fig. 3 was observed. Figure 5 shows the salt effect for $\mathrm{pH} 10$ solution, which shows the highest non-surface activity. Again, the solution showed very good foam formation after addition of $0.1 \mathrm{M} \mathrm{NaCl}$.

\section{Surface tension and cmc determination}

Figures 6(a) and (b) show the polymer concentration dependence of surface tension 
of the solutions and SLS intensity for $\mathrm{St}_{44}-b-\mathrm{AA}_{92}$ in pure water and in $0.1 \mathrm{M} \mathrm{NaCl}$ aq., respectively. In pure water, the surface tension did not show a marked decease, but rather a flat behavior, although the data points are somewhat scattered. However, in $0.1 \mathrm{M} \mathrm{NaCl}$ solution, the surface tension started to decrease at certain polymer concentration, although not so sharply, like a typical ionic low molecular weight surfactant. This observation agrees with the foam formation observation discussed above, indicating that the polymer change from non-surface active to surface active by salt addition. The static light scattering (SLS) intensity was also plotted in these figures. The SLS intensity increased with increasing polymer concentration, but a clear bending point is observed in both cases. This sudden increase of the slope is due to the micelle formation, i.e., the concentration of the bending point is cmc. In pure water, no marked surface tension change is observed although a clear cmc is detected, which is typical behavior of non-surface active polymers. In a salt solution, both bending points in surface tension and SLS intensity appeared at the same polymer concentration. Although cmc has been determined by the concentration where surface tension decrease stops (i.e., becomes flat) for common surfactants, it has often been observed for non-surface active system that $\mathrm{cmc}$ is located at the concentration where the surface tension starts to decrease.

Figures 6(c) and (d) show the pH effect on the surface tension and SLS intensity for $\mathrm{St}_{44}-b-\mathrm{AA}_{92}$. At $\mathrm{pH} 3$, the surface tension showed a clear bending point as for common surfactants although its decrease with polymer concentration is not so large. In addition, this bending point agreed with the cmc determined by SLS intensity. Hence, this polymer behaves as a surfactant under $\mathrm{pH}$ 3. Since the AA block is protonated, this block copolymer is not an “ionic" amphiphilic diblock copolymer, but mostly a non-ionic amphiphilic diblock copolymer, although $\mathrm{COOH}$ units might be very slightly dissociated. However, at $\mathrm{pH} 10$ 
(Fig.6d), no marked surface tension decrease was observed although cmc could be clearly determined by SLS measurement. This is typical behavior of non-surface active polymers. The surface tension data is somewhat scattered, but the small "drop" of surface tension near cmc might have a physical meaning. We observed similar behavior, i.e., small surface tension decrease near cmc, for other non-surface active polymers, and named it "M-Point"[1]. We could not understand its meaning and interpretation at that stage, but this point was repeatedly observed, and we are convinced that this is not an experimental error. Recently, not only an image charge effect but also very stable micelle formation has been clarified to be an essential factor as an origin of non-surface activity[5,6]. According to this concept, one interpretation of this M-point might be possible; with increasing polymer concentration, the surface tension of the solution starts to decrease at certain concentration like common surfactant since the polymer has hydrophobic block, i.e., amphiphilic. However, at the same time, micelle associates start to be formed since this concentration is located near cmc. Once micelles are formed, and the micelle situation is more stable than that in an adsorbed state, which is largely destabilized by image charge repulsion, the equilibrium between adsorption and micelle (via unimer) is in favor of micelle formation, so the surface tension decrease stops. This interpretation might be just speculation at this stage, but is in agreement with our interpretation on the origin of non-surface activity.

\section{Salt and pH effect on cmc}

One of the special characteristics of non-surface active polymers is the peculiar added salt dependence of cmc; cmc increases with increasing added salt concentration for both strongly anionic and cationic amphiphilic block copolymers. The Corrin-Harkins 
law[42] is a famous, traditional concept for salt concentration dependence of cmc for low molecular weight ionic surfactants, which suggests decrease of $\mathrm{cmc}$ with salt concentration increase. This behavior is commonly observed for many ionic surfactants and has been interpreted as the effect of shielding of electrostatic repulsion between ionic head group of surfactants in the micelle. Hence, the behavior of non-surface active polymers is quite unique and its mechanism is interesting. Figure 7 shows the added $\mathrm{NaCl}$ concentration dependence of cmc for PSt- $b$-PAA block copolymers with a different block ratio at a neutral $\mathrm{pH}$. For all three polymers investigated, cmc increased, with increasing salt concentration as found in our previous study. Hence, this unique property is common for non-surface active polymers. Since the effect of added salt on the ionic "head group" repulsion in the micelle should be, in principle, the same for common ionic surfactants and ionic block copolymers, we believe that the origin of this unique property is the shielding effect on the image charge repulsion at the air/water interface. The adsorbed state is highly destabilized by image charge repulsion. On the other hand, the polymer micelle is very stable. This combination is essential for non-surface activity. By salt addition, image charge repulsion, which is electrostatic, is also shielded by added salt. Hence, the equilibrium between adsorbed state and micelle state via unimer state forwards to adsorbed state, which results in harder micelle formation, i.e., increase of cmc. Increase of adsorbed polymers at the air/water interface can be confirmed by foam formation as shown in Fig.3. Foam was formed by the addition of salt while less foam if any in the absence of salt. In addition, the adsorbed polymer was directly confirmed by X-ray reflectivity for strongly anionic polymer[2-4].

Since the present polymer is a weakly acidic polymer, $\mathrm{pH}$ dependence of $\mathrm{cmc}$ is also an interesting topic. Non-surface active / surface active transition by $\mathrm{pH}$ change is 
already confirmed by foam formation observation (Fig.4) and surface tension experiments (Figs. 6(b), 6(c)). The cmc of the three block copolymers differed with the $\mathrm{pH}$. Cmc showed a minimum at a neutral $\mathrm{pH}$ (Fig.8). This behavior can be reasonably explained if we recall that this polymer is non-surface active at a neutral $\mathrm{pH}$ but is surface active at low and high $\mathrm{pH}$ conditions as was observed in foam formation and surface tension experiments. When surface active, cmc is very low and it becomes higher when adsorption of polymers at the air/water interface occurs. Polymers are non-surface active at a neutral $\mathrm{pH}$ since they are dissociated to be anionic while they are surface active at low and high $\mathrm{pHs}$ since they are protonated (non-ionic) and influenced by the added salt $(\mathrm{NaOH}$ in this case), respectively. It might be better to say that cmc is lowered by image charge repulsion and this is the origin of the non-surface activity. Micelles are formed at a very low polymer concentration before adsorption occurs since they are repelled from the air/water interface by image charge repulsion.

It might be interesting to note that the surface tension started to decrease at $\mathrm{cmc}$ determined by SLS in Figure 6(b). This looks very strange behavior. The non-surface active substance showed almost no surface tension reduction like in Fig.6(a), while the surface active substance shows bending point in surfacce tension vs. concentration curve at cmc evaluated by SLS, like in Fig.6(c). The substances which are not perfectly surface non-active and also not perfectly active often show this kind of behavior; start of surface tension reduction at cmc. Its origin is not clarified yet, but similar behavior was observed previously for other polymers [3], which can be understood as just a transition state.

\section{Confirmation of Micelle Formation and its Size by DLS and AFM}


Existence of micelles above cmc and micelle size was confirmed by dynamic light scattering (DLS) and atomic force microscopy (AFM). Figure 9a is an example of the time-correlation function of the scattered field and its double-exponential fitting, and $9 \mathrm{~b}$ is the decay rate $(\Gamma)$ vs. $q^{2}$ ( $q$ : scattering vector, $q=4 \pi \sin (\theta / 2) / \lambda, \theta$ the scattering angle, $\lambda$ the wave length of the laser $(632.8 \mathrm{~nm})$, and $n$ the refractive index) plot. We found two dynamic modes, one (faster) is for polymer micelle, and the other (slower) is a large aggregate, whose contribution is very small as found in our previous studies. The excellent linearity with passage through the origin in Fig.9b means that both modes are for translational diffusion, and from its slope we can calculate the translational diffusion coefficient, which can be converted to a hydrodynamic radius $\left(R_{\mathrm{h}}\right)$ by applying the Stokes-Einstein equation.

At a low polymer concentration, $R_{\mathrm{h}}$ of $\mathrm{St}_{58}-b-\mathrm{AA}_{142}$ decreased with increasing added salt $(\mathrm{NaCl})$ concentration (Fig.10). This is an observation typical for ionic polymer micelles, which can be explained by shrinking of corona chains, which were extended to some extent at a low ionic strength, by an electrostatic shielding effect. Taking into consideration the fact that the fully stretched chain length of this polymer (total degree of polymerization is 200) is about $50 \mathrm{~nm}$, shrinking from slightly more than $50 \mathrm{~nm}$ is reasonable and has been observed in our previous studies. The remarkable difference from the strongly ionic polymer micelle[3,4] is the absence of "critical salt concentration". Since the present polymer is weakly ionic polymer micelle, the charge density in the corona is not so high. Hence, added salt ions can go into the corona region at low salt conditions. At a higher salt concentration, no remarkable change of $R_{\mathrm{h}}$ with increasing salt concentration was observed. This might be due to the fact that the ionic strength in the system is already high enough due to the high polymer concentration, so the system itself was no longer sensitive to ionic strength. We should note 
the smaller $R_{\mathrm{h}}$ value for high polymer concentration condition. This might be due to the change (decrease) of aggregation number of the micelle. In fact, decrease of aggregation number due to enhanced "head group" repulsion by shrinking corona chain was reported for weakly ionic polymer micelle by Imae et al.[43] However, further study is necessary to confirm this point.

The $\mathrm{pH}$ dependence of $R_{\mathrm{h}}$ is shown in Fig.11. Quite different $\mathrm{pH}$ dependence was observed for three different polymer concentrations; $R_{\mathrm{h}}$ showed maximum, insensitivity, and minimum as a function of $\mathrm{pH}$ for lower, middle, and higher polymer concentration conditions. We have no clear idea for interpretation of this observation at this stage, one speculative explanation might be as follows. At a low polymer concentration, the dissociation number of carboxylic acid units on the corona chain increased with increasing $\mathrm{pH}$, which results in extension of corona chain. However, at a higher $\mathrm{pH}$ than the neutralization point, the added $\mathrm{NaOH}$ to control $\mathrm{pH}$ acted as an added salt, causing the corona chain to shrink by electrostatic screening effect due to the excessive $\mathrm{NaOH}$ ions. At a higher polymer concentration, we should take the effect of intermicellar electrostatic interaction, which apparently lowers the $R_{\mathrm{h}}$ value than its real physical size. ${ }^{44}$ This effect became remarkable with increasing $\mathrm{pH}$, but since the added $\mathrm{NaOH}$ act as added salt, $R_{\mathrm{h}}$ value approached to its real size of about $25 \mathrm{~nm}$, which is a reasonable value since fully-stretched chain length of this polymer is about $35 \mathrm{~nm}$. Further detailed experiments and analyses are necessary to understand the behavior of weakly ionic polymer micelles, which should be our future target.

Figure 12 shows an example of an AFM image for $\mathrm{St}_{44}-b-\mathrm{SS}_{92}$ micelles. Almost spherical micelles with a radius of about $21 \mathrm{~nm}$ are clearly discerned. This radius is a suitable value for a dry size since $R_{\mathrm{h}}$ of this micelle converged into about $25 \mathrm{~nm}$ as shown in Fig.11. 


\section{Conclusions}

The weakly ionic amphiphilic diblock copolymers, $\mathrm{St}_{\mathrm{m}}-b-\mathrm{SS}_{\mathrm{n}}$ were synthesized by nitroxy radical-mediated living radical polymerization. This polymer was surface active under acidic conditions but it showed non-surface activity at a neutral $\mathrm{pH}$, and slightly surface active under alkaline conditions since added $\mathrm{NaOH}$ played a role as an added salt. Hence, we have established the transition between surface active / non-surface active by changing $\mathrm{pH}$, for the first time to our best knowledge. Under a non-surface active condition, cmc of the micelle showed an added salt concentration dependence similar to that of other non-surface active polymers studied previously; cmc increased with increasing added salt concentration. Cmc showed a unique $\mathrm{pH}$ dependence, but this was interpreted by the change of charge number on the PAA block and $\mathrm{NaOH}$ concentration of the added salt. These observations did not conflict with the proposed origin of non-surface activity; the key factors are electrostatic image charge repulsion at the air/water interface and high stability of the polymer micelle in the bulk solution. In other words, non-surface activity can be explained by the change of balance between unimer, adsorbed polymer, and micelle as shown in Figure 13. Control of surface active /non-surface active transition will be new practical technique to establish novel functional materials and devices, especially related to surface and interface sciences.

\section{Acknowledgement}

This work was supported by a grant-in-aid for Scientific Research on Innovative Areas "Molecular Soft-Interface Science" (20106006) and B19350058 from the Ministry of Education, Culture, Sports, Science and Technology of Japan, to which our sincere gratitude 
is due. This work was also supported by the Global COE Program, GCOE for the International Center for Integrated Research and Advanced Education in Material Science. A.G. expresses his sincere thanks to the Japan Society for the Promotion of Science (JSPS) for the Postdoctoral Fellowships for Foreign Researchers.

\section{References}

1. Matsuoka H, Matsutani M, Mouri E, Matsumoto K (2003) Polymer Micelle Formation without Gibbs Monolayer Formation --- Synthesis and Characteristics of Amphiphilic Diblock Copolymer having Sulfonic Acid Groups, Macromolecules, 36(14), 5321-5330.

2. Matsuoka H, Maeda S, Kaewsaiha P, Matsumoto K (2004) Micellization of Non-Surface Active Diblock Copolymer in Water. --- Special Characteristics of Poly(styrene)-block-Poly(styrenesulfonate)---, Langmuir, 20(18), 7412-7421

3. Kaewsaiha P, Matsumoto K, Matsuoka H (2005) Non-Surface Activity and Micellization of Ionic Amphiphilic Diblock Copolymers in Water, Langmuir, 21(22), 9938-9945.

4. Kaewsaiha P, Matsumoto K, Matsuoka H (2007) Sphere to Rod Transition of Non-Surface Active Amphiphilic Diblock Copolymer Micelles --- A Small-Angle Neutron Scattering Study --- Langmuir, 23(18), 9162-9169.

5. Matsuoka H, Chen H, Matsumoto K, Molecular Weight Dependence of Non-Surface Activity for Ionic Amphiphilic Diblock Copolymers, Soft Matter, 8(35), 9140-9146.

6. Matsuoka H, Hachisuka M, Uda K, Onishi T, Ozoe S (2012) Why Ionic Amphiphilic "Block" Copolymer can be Non-Surface Active? Comparison of Homopolymer, Block and 
Random Copolymers of Poly(styrenesulfonate), Chem.Lett., 41(10), 1063-1065.

7. Matsumoto K, Ishizuka T, Harada T, Matsuoka H (2004) Association Behavior of Fluorine-Containing and Non-Fluorine-Containing Methacrylate-Based Amphiphilic Diblock Copolymer in Aqueous Media, Langmuir 20(17), 7270-7282.

8. Nayak RR, Yamada T, Matsuoka H (2011) Non-Surface Activity of Cationic Amphiphilic Diblock Copolymers, IOP Conference Series: Materials Science and Engineering, 24, 012024.

9. Ghosh A, Yusa S, Matsuoka H, Saruwatari Y (2011) Non-Surface Activity and Micellization Behavior of Cationic Amphiphilic Block Copolymer Synthesized by Reversible Addition - Fragmentation Chain Transfer Process, Y. Langmuir, 27(15), 9237-9244.

10. Jackson JD(1998) Classical Electrodynamics, 3rd ed., Wiley, New York, Chapter 4.

11. Onsager L, Samaras NNT (1934) The Surface Tension of Debye-Hückel Electrolytes. $J$. Chem. Phys. 2(8), 528-536.

12. Ikeda S (1986) Colloid Chemistry, Shokabo, Tokyo, Chapter 4 (in Japanese).

13. Wittmer J, Joanny JF (1993) Charged diblock copolymers at interfaces. Macromolecules, 26(11), 2691-2697.

14. Amiel C, Sikka M, Schneider JW, Tsao YH, Tirrell M, Mays JW (1995) Adsorption of Hydrophilic-Hydrophobic Block Copolymers on Silica from Aqueous Solutions, Macromolecules, Macromolecules 28(9), 3125-3134.

15. Sen AK, Roy R, Juvekar VA (2007) Effect of structure on solution and interfacial properties of sodium polystyrene sulfonate (NaPSS). Polym.Int'l, 56(2), 167-174.

16. Caminati G, Gabrielli G (1993) Polystyrene sulfonate adsorption at water-graphon and 
water-air interfaces. Coll\&Surf.A, 70, 1-14.

17. Yim H, Kent M, Matheson A, Ivkov R, Satija S, Majewski J, Smith GS (2000) Adsorption of Poly(styrenesulfonate) to the Air Surface of Water by Neutron Reflectivity. Macromolecules 33(16), 6126-6133.

18. Yim H, Kent M, Matheson A, Stevens MJ, Ivkov R, Satija S, Majewski, J, Smith GS (2002) Adsorption of Sodium Poly(styrenesulfonate) to the Air Surface of Water by Neutron and X-ray Reflectivity and Surface Tension Measurements: Polymer Concentration Dependence. Macromolecules 35(26), 9737-9747.

19. An SW, Su TJ, Thomas RK, Baines FL, Billingham NC, Armes SP, Penfold J (1998) Neutron Reflectivity of an Adsorbed Water-Soluble Block Copolymer: A Surface Transition to Micelle-like Aggregates at the Air/Water Interface, J. Phys. Chem. B 102(2), 387-393.

20. An SW, Thomas RK, Baines FL, Armes SP, Billingham NC, Penfold J (1998) Neutron Reflectivity of an Adsorbed Water-Soluble Block Copolymer at the Air/Water Interface: The Effects of $\mathrm{pH}$ and Ionic Strength, J. Phys. Chem. B 102(26), 5120-5126.

21. An SW, Su TJ, Thomas RK, Baines FL, Billingham NC, Armes SP, Penfold J (1998) Neutron Reflectivity of Adsorbed Water-Soluble Block Copolymers at the Air/Water Interface: the Effects of Composition and Molecular Weight, Macromolecules 31(22), 7877-7885.

22. Guenoun P, Davis HT, Mays JW, Tirrell M (1996) Aqueous Micellar Solutions of Hydrophobically Modified Polyelectrolytes, Macromolecules 29(11), 3965-3969.

23. Fontaine P, Daillant J, Guenoun P, Alba M, Braslau A, Mays J, Petit JM, Rieutord F (1997) Spontaneous buckling induced by the adsorption of charged copolymers at the air-water interface. J. Phys. II (France) 7(3), 401-407. 
24. Rager T, Meyer WH, Wegner G, Mathauer K, Mächtle W, Schrof W, Urban D (1999) Block copolymer micelles as seed in emulsion polymerization. Macromol. Chem. Phys. 200(7), 1681-1691.

25. Iddon PD, Robinson KL, Armes SP (2004) Polymerization of sodium 4-styrenesulfonate via atom transfer radical polymerization in protic media. Polymer 45(3), 759-768.

26. Garnier S, Laschewsky S (2006) New Amphiphilic Diblock Copolymers: Surfactant Properties and Solubilization in Their Micelles. Langmuir 22(9), 4044-4053.

27. Eghbali E, Colombani O, Drechsler M, Müller AHE, Hoffmann H (2006) Rheology and Phase Behavior of Poly(n-butyl acrylate)-block-poly(acrylic acid) in Aqueous Solution, Langmuir 22(10), 4766-4776.

28. Oikonomou EK, Bethani A, Bokias G, Kallitsis JK (2011) Poly(sodium styrene sulfonate)-b-poly(methyl methacrylate) diblock copolymers through direct atom transfer radical polymerization: Influence of hydrophilic-hydrophobic balance on self-organization in aqueous solution. Eur. Polym. J. 47(4), 752-761.

29. Liénafa L, Oberdisse J, Mora S, Monge S, Robin J-J (2011) Rheology and SANS on PET- $b$-PLAc- $b$-P(DMAEMAq) Triblock Copolymers: Impact of the PET and Polyelectrolyte Chain Length. Macromolecules 44(13), 5326-5335.

30. Jacquin M, Muller P, Cottet H, Théodoly O (2010) Self-Assembly of Charged Amphiphilic Diblock Copolymers with Insoluble Blocks of Decreasing Hydrophobicity: From Kinetically Frozen Colloids to Macrosurfactants, Langmuir 26(24), 18681-18693.

31. Théodoly O, Jacquin M, Muller P, Chhun S (2009) Adsorption Kinetics of Amphiphilic Diblock Copolymers: From Kinetically Frozen Colloids to Macrosurfactants. Langmuir 25(2), 781-793. 
32. Jacquin M, Muller P, Talingting-Pabalan R, Cottet H, Berret J.-F, Futterer T, Théodoly O (2007) Chemical analysis and aqueous solution properties of charged amphiphilic block copolymers PBA-b-PAA synthesized by MADIX((c)). J. Colloid Interface Sci. 316(2), 897-911.

33. Jaeger W, Bohrisch J, Laschewsky A (2010) Synthetic polymers with quarternary nitrogen atoms - synthesis and structure of the most used type of cationic polyelectrolytes. Prog Polym Sci., 35(5), 511-77.

34. Berndt E, Behnke S, Ulbricht M (2011) Influence of alkyl chain length and molecular weight on the surface functionalization via adsorption/entrapment with biocidal cationic block copolymers, European Polymer Journal 47(12), 2379-2390

35. Zhao W, Fonsny P, FitzGerald P, Warra GG, Perrier S (2013) Unexpected behavior of polydimethylsiloxane/poly(2-(dimethylamino)ethyl acrylate) (charged) amphiphilic block copolymers in aqueous solution. Polym. Chem. 4(6), 2140-2150.

36. Tozuka Y, Higashi K, Morita T, Nishikawa M, Uchiyama H, Zhan J, Moribe K, Nishikawa K, Takeuchi H, Yamamoto K (2012) Transglycosylated rutin-specific non-surface-active nanostructure affects absorption enhancement of flurbiprofen. European Journal of Pharmaceutics and Biopharmaceutics 82(1), 120-126

37. Maeda H (2012) An Electrostatic Model for the Unusual Salt Effect on the Stability of Ionic Copolymer Micelles. Chem.Lett. 41(10) , 1057-1059

38. Ghosh A, Yusa S, Matsuoka H, Saruwatari Y (2010) Synthesis of Cationic Amphiphilic Block Copolymer by Reversible Addition - Fragmentation Chain Transfer Process and Their Self-assembly Studies. Polym.Prep.Jpn, 59(1), 834-834

39. Benoit D, Chaplinski V, Braslau R, Hawker CJ (1999) Development of a universal 
alkoxyamine for "living" free radical polymerizations. J. Am.Chem.Soc. 121(16), 3904-3920.

40. Chu B (1991) Laser Light Scattering, Basic Principles and Practice, 2nd ed. Boston, Academic Press.

41. Matsuoka H, Ogura Y, Yamaoka H (1998) Effects of Counterioin Species on the Dynamics of Polystyrenesulfonate in Aqeous Solution as Studied by Dynamic Light Scattering. J.Chem.Phys. 109(14), 6125-6132.

42. Corrin ML, Harkins WD (1947) The Effect of Salts on the Critical Concentration for the formation of micelles in colloidal electrolytes. J. Am. Chem. Soc., 69(3), 683-688.

43. Imae T (2001) Morphology and Nanostructure of Amphiphilic Polymer Micelles with Fluorinated Core and Nonfluorinated Corona. Kobunshi Ronbunshu 58(4), 178-188 (in Japanese).

44. Degiorgio V, Corti M, Giglio M eds., (1980) Light Scattering in Liquids and Macromolecular Solutions, Plenum.

\section{Figure Captions}

Scheme 1. Synthesis of PSt- $b$-PAA.

Figure $1 .{ }^{1} \mathrm{H}$ NMR spectrum of polymers in polymerization process. 
Figure 2. GPC charts of PSt and PSt- $b$-Pt-BuAc.

Figure 3. Observation of foam formation of $\mathrm{St}_{44}-b-\mathrm{AA}_{92}$ with and without added salt.

Figure 4. Observation of foam formation of (a) $\mathrm{St}_{50}-b-\mathrm{AA}_{51}$ and (b) $\mathrm{St}_{44}-b-\mathrm{AA}_{92}$ under different $\mathrm{pH}$ conditions.

Figure 5. Observation of foam formation of $\mathrm{St}_{44}-b-\mathrm{AA}_{92}$ with and without added salt at $\mathrm{pH} 10$.

Figure 6. SLS and surface tension results for (a) $\mathrm{St}_{44}-b-\mathrm{AA}_{92}$ (b) $\mathrm{St}_{44}-b-\mathrm{AA}_{92}$ with $0.1 \mathrm{M} \mathrm{NaCl}$,

(c) $\mathrm{St}_{44}-b-\mathrm{AA}_{92}$ at $\mathrm{pH} 3$, (d) $\mathrm{St}_{44}-b-\mathrm{AA}_{92}$ at $\mathrm{pH} 10$.

Figure 7. Salt concentration dependence of CMC for three block copolymers.

Figure 8. pH dependence of CMC for three block copolymers.

Figure 9. Time correlation function at $60^{\circ}$ of $\mathrm{St}_{44}-b-\mathrm{AA}_{92}$ (a) and $\Gamma$ vs $q^{2}$ plot (b).

Figure 10. Salt concentration dependence of $\mathrm{R}_{\mathrm{h}}$ of $\mathrm{St}_{58}-b-\mathrm{AA}_{142}$.

Figure 11. $\mathrm{pH}$ dependence of $\mathrm{R}_{\mathrm{h}}$ of $\mathrm{St}_{44}-b-\mathrm{AA}_{92}$.

Figure 12. AFM image and line profile of $\mathrm{St}_{44}-b-\mathrm{AA}_{92}$. Polymer concentration of the aqueous solution used for sample preparation was $0.1 \mathrm{mg} / \mathrm{ml}$.

Figure 13. Equilibrium for non-surface active polymers in aqueous solution (a) and schematic representation of image charge effect at the air/water interface (b). Since the adsorbed state at the air/water interface is highly destabilized by image charge repulsion and also since the polymer micelles in bulk solution are so stable, the equilibrium is in favor of micelle formation. 

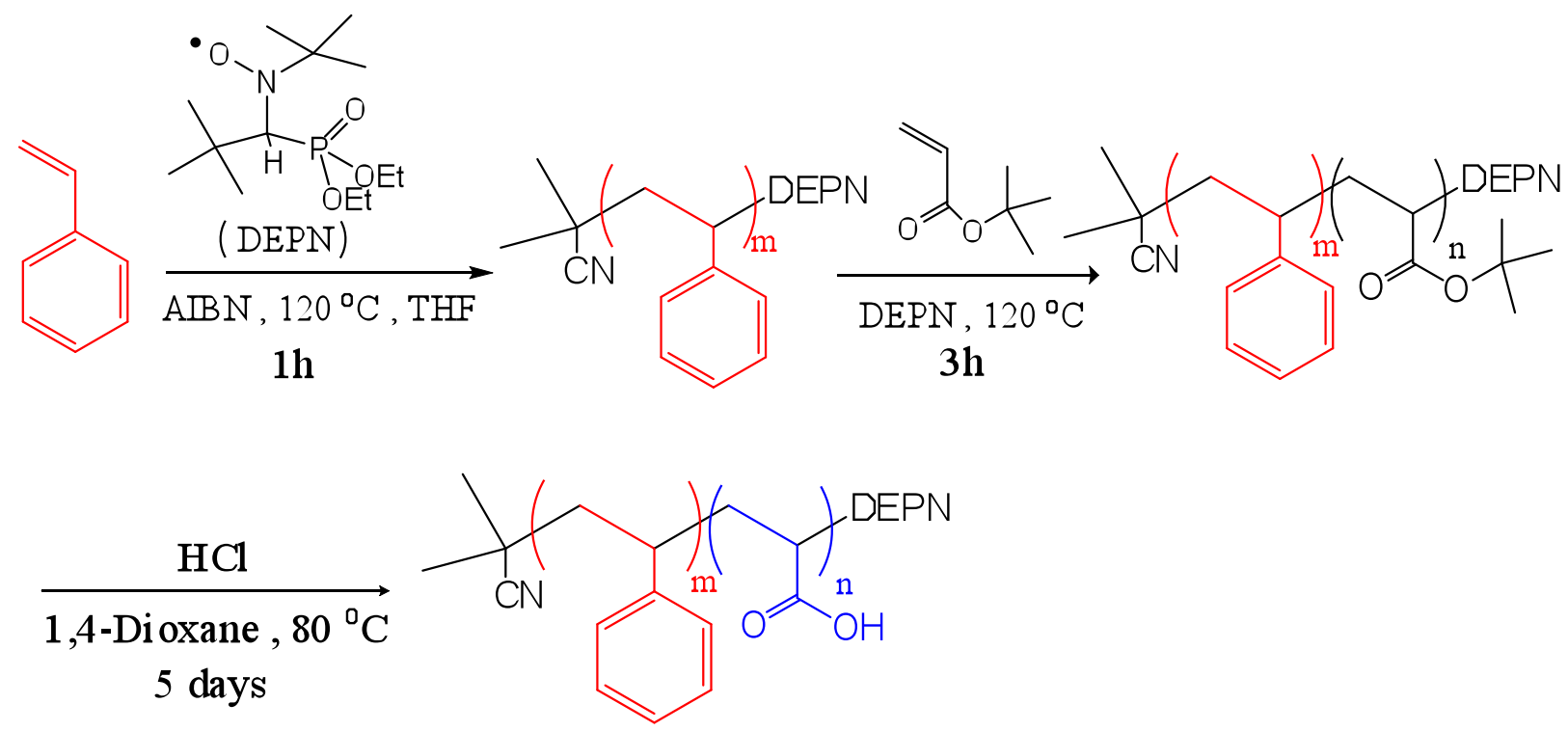

Scheme 1. Synthesis of PSt- $b$-PAA. 

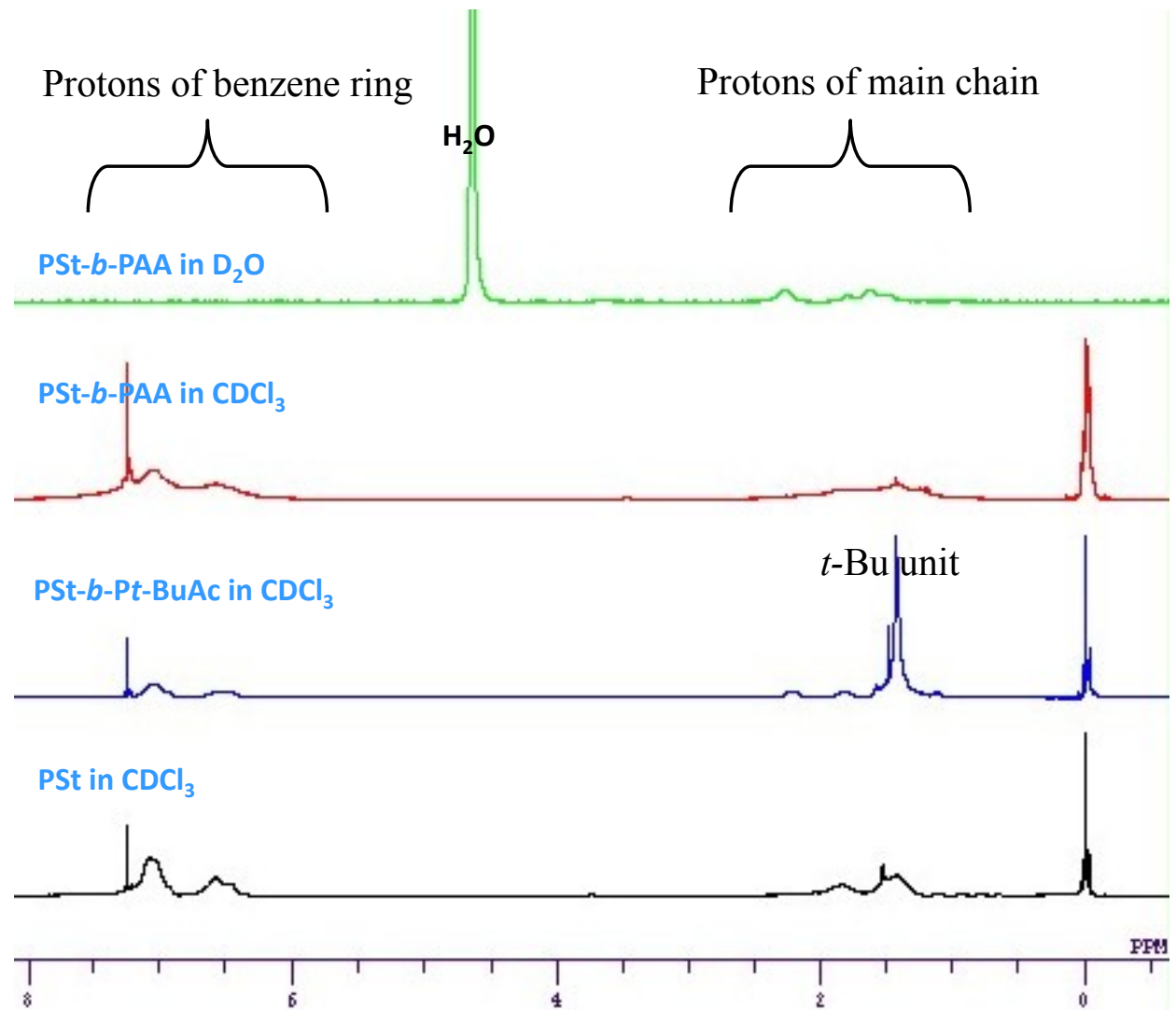

Figure 1. ${ }^{1} \mathrm{H}$ NMR spectrum of polymers in polymerization process. 


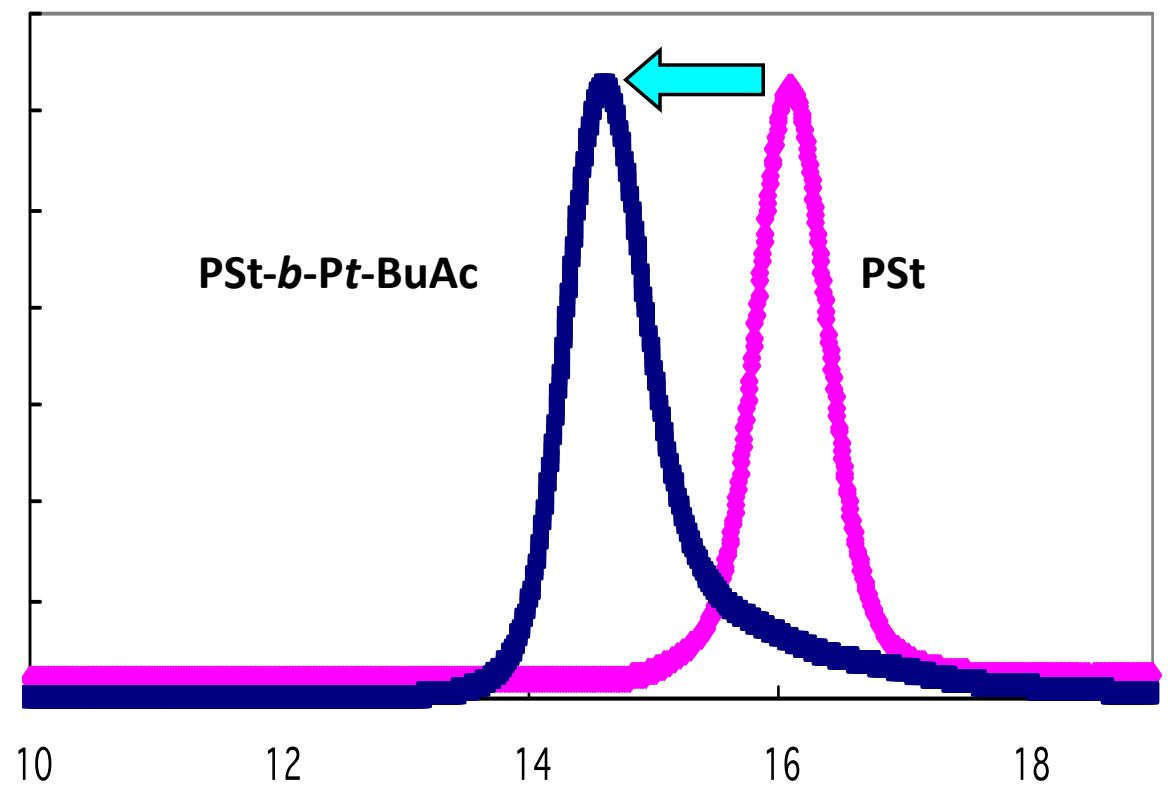

Figure 2. GPC charts of PSt and PSt- $b-\mathrm{P} t$-BuAc.

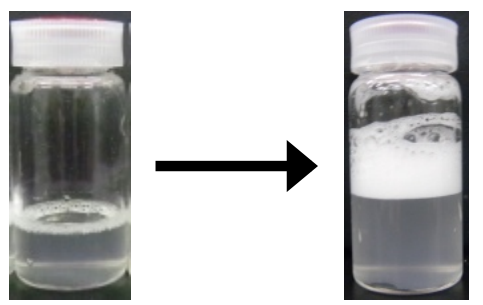

In pure water

With $0.1 \mathrm{M} \mathrm{NaCl}$

Figure 3. Observation of foam formation of $\mathrm{St}_{44}-b-\mathrm{AA}_{92}$ with and without added salt. 
(a)

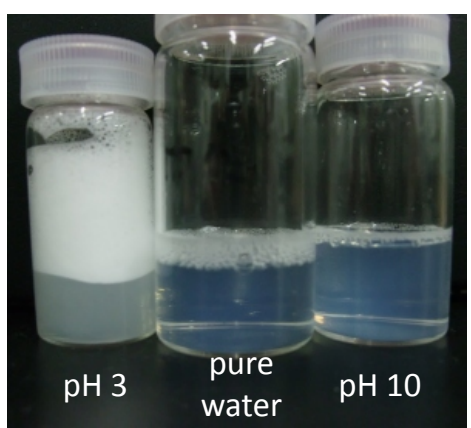

(b)

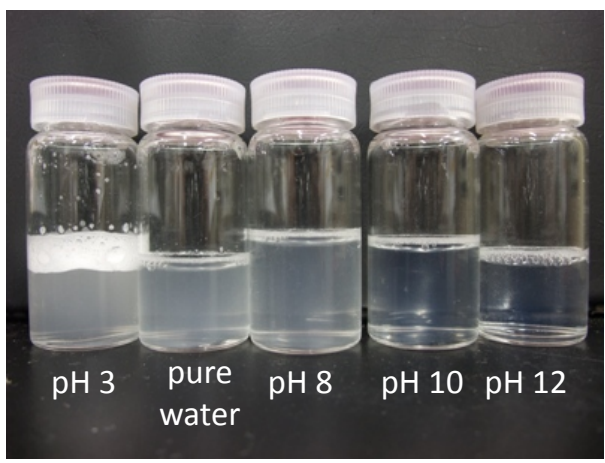

Figure 4. Observation of foam formation of (a) $\mathrm{St}_{50}-b-\mathrm{AA}_{51}$ and (b) $\mathrm{St}_{44}-b-\mathrm{AA}_{92}$ under different $\mathrm{pH}$ conditions.

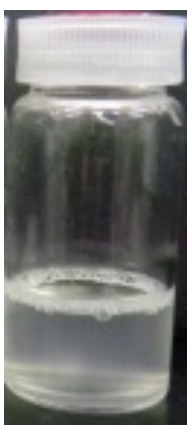

(a) $\mathrm{pH} 10$

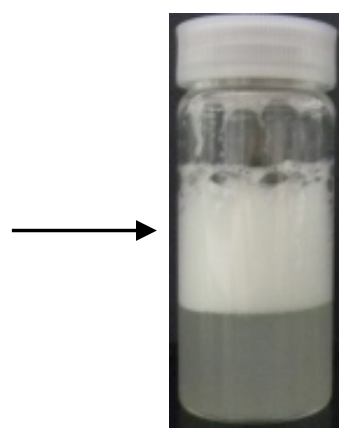

(b) $\mathrm{pH} 10$ with $0.1 \mathrm{M} \mathrm{NaCl}$

Figure 5. Observation of foam formation of $\mathrm{St}_{44^{-}}$ $b$ - $\mathrm{AA}_{92}$ with and without added salt at $\mathrm{pH} 10$. 

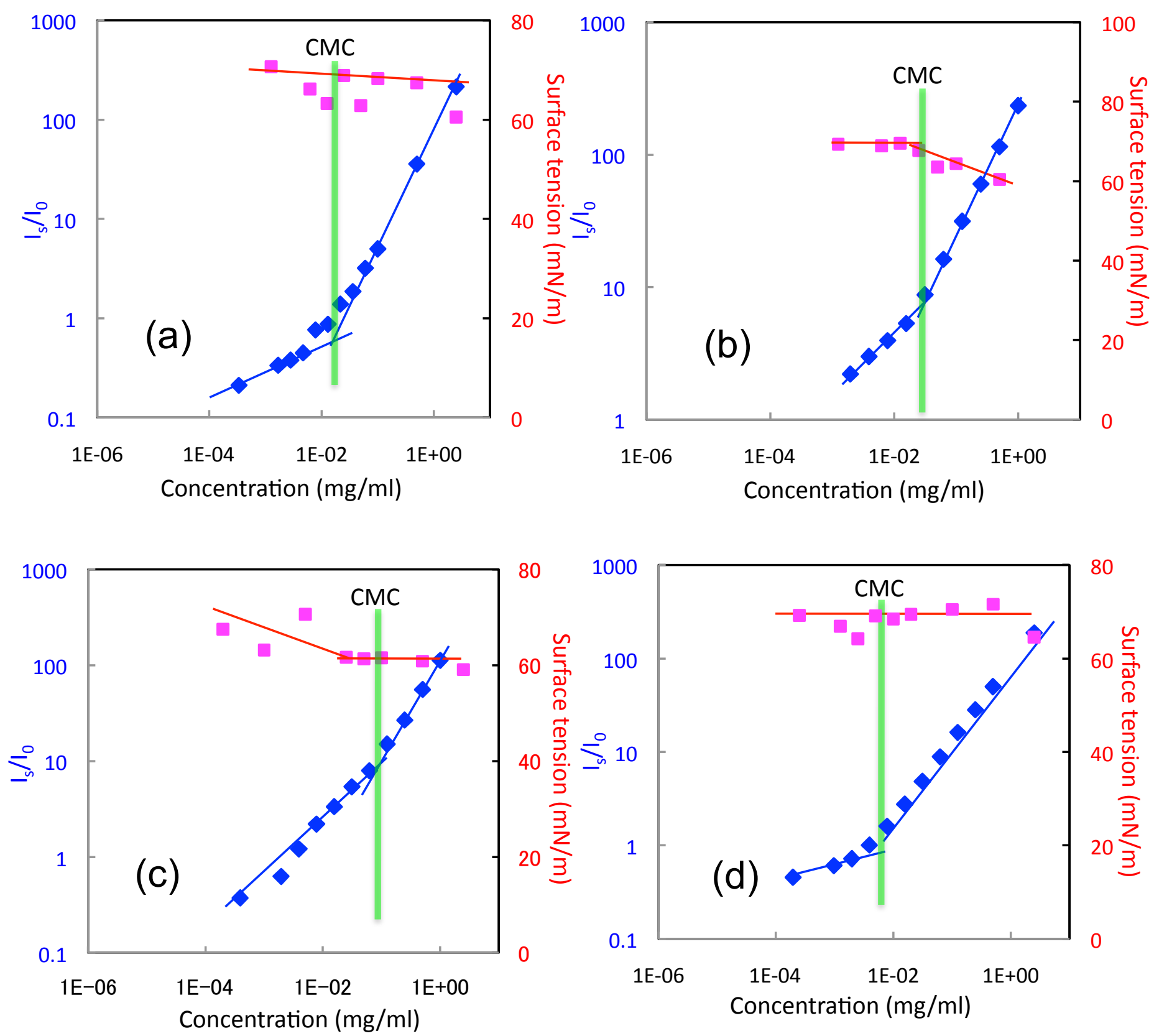

Figure 6. SLS and surface tension results for (a) $\mathrm{St}_{44}-b-\mathrm{AA}_{92}$, (b) $\mathrm{St}_{44}-b-\mathrm{AA}_{92}$ with $0.1 \mathrm{M}$ $\mathrm{NaCl}$, (c) $\mathrm{St}_{44}-b-\mathrm{AA}_{92}$ at $\mathrm{pH} 3$,(d) $\mathrm{St}_{44}-b-\mathrm{AA}_{92}$ at $\mathrm{pH} 10$. 


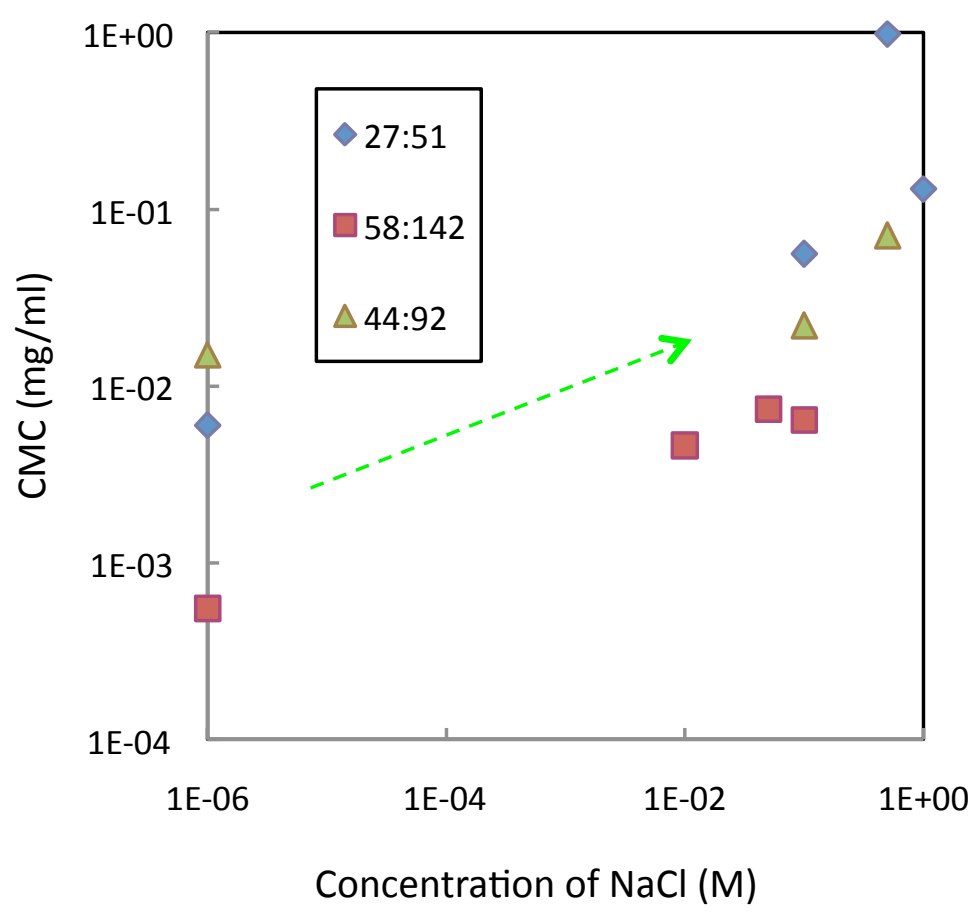

Figure 7. Salt concentration dependence of CMC for three block copolymers.

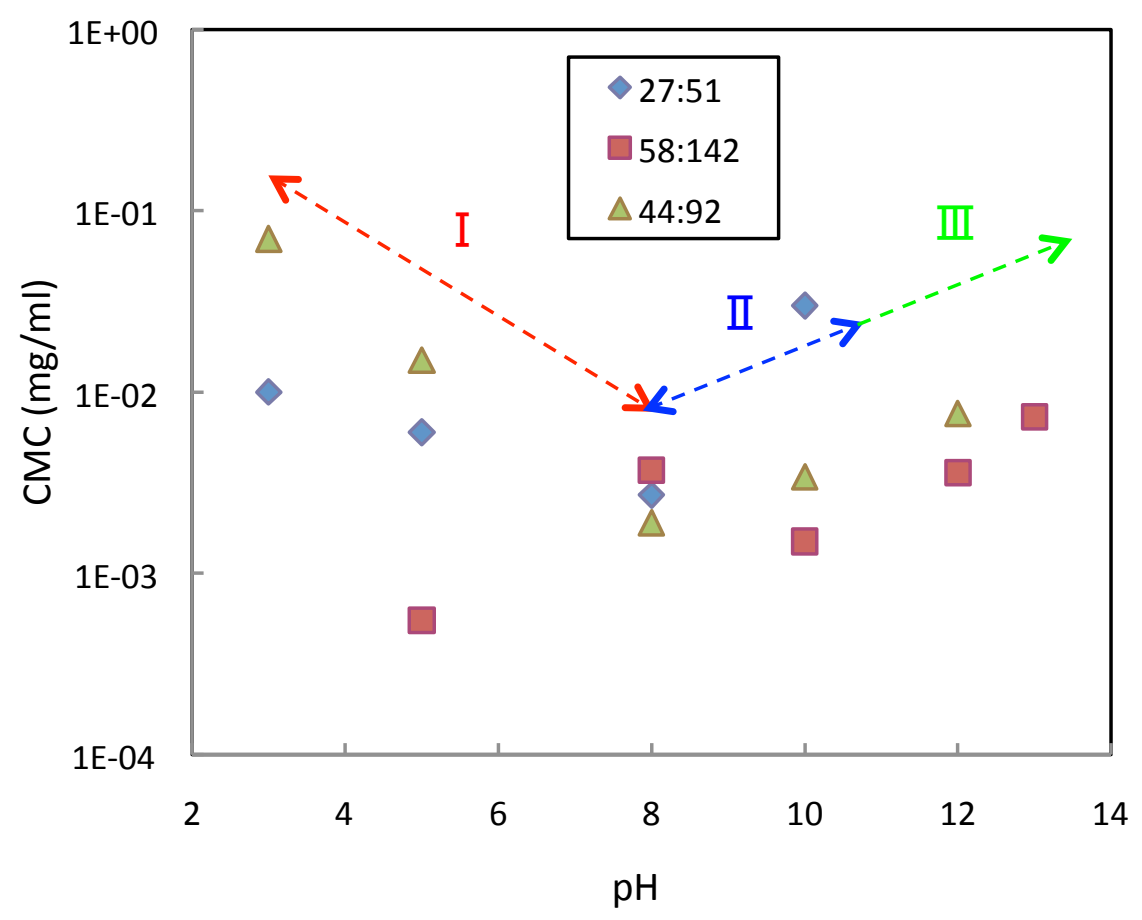

Figure 8. $\mathrm{pH}$ dependence of CMC for three block copolymers. 

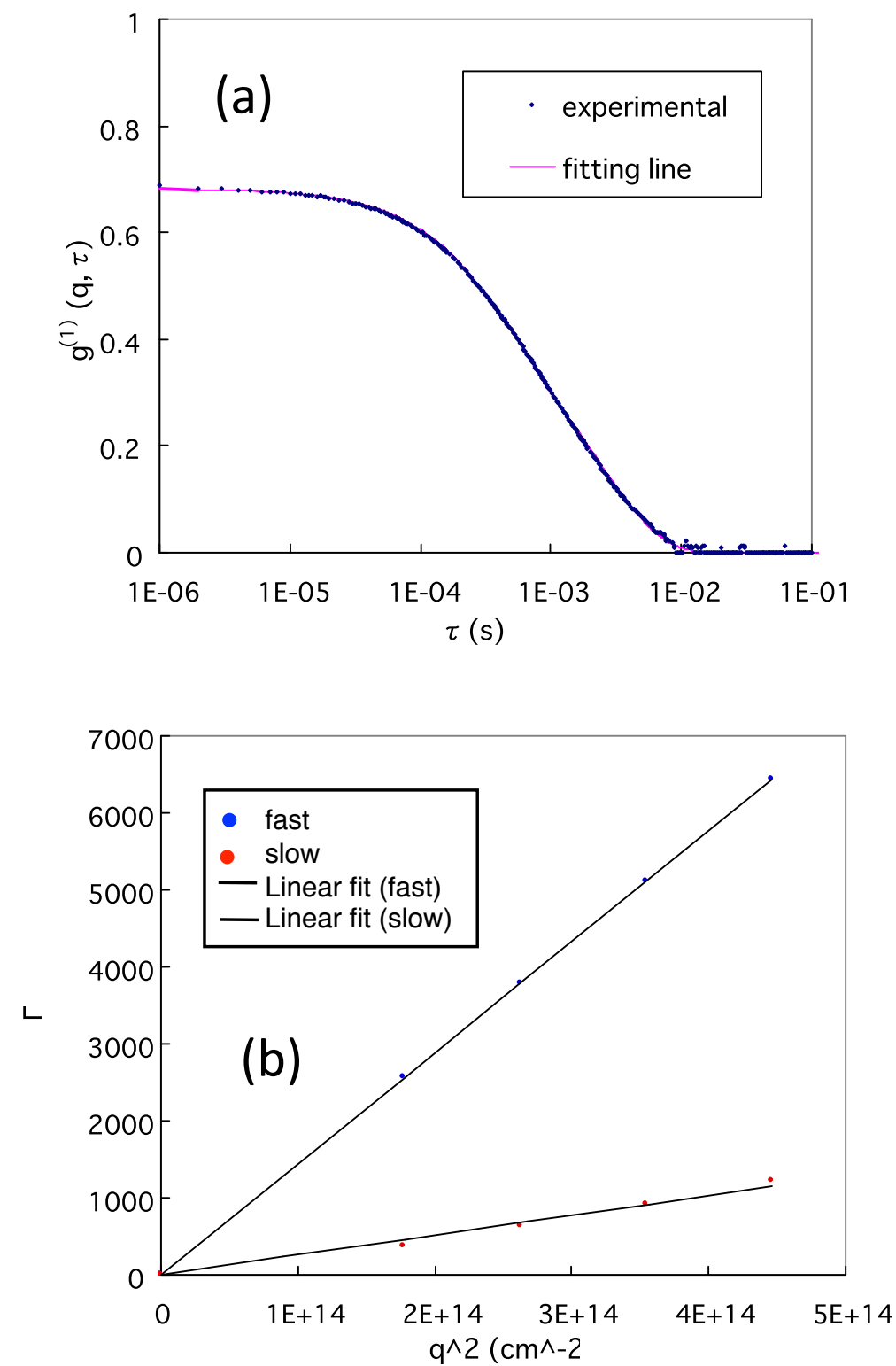

Figure 9. Time correlation function at $60^{\circ}$ of $\mathrm{St}_{44^{-}}$ $b-\mathrm{AA}_{92}$ (a) and $\Gamma v s q^{2}$ plot (b). 


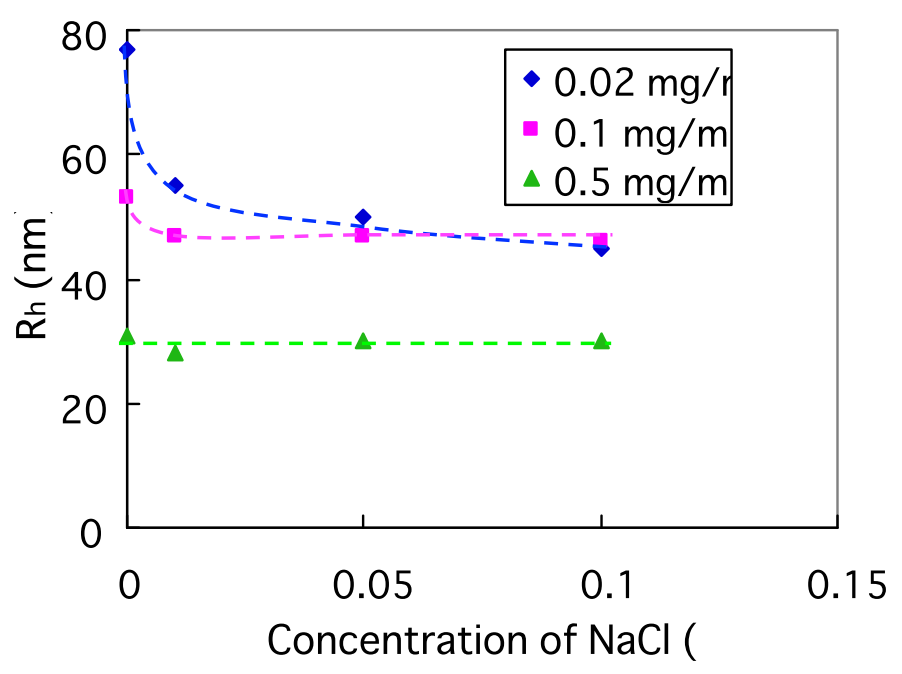

Figure 10. Salt concentration dependence of $\mathrm{R}_{\mathrm{h}}$ of $\mathrm{St}_{58}-b-\mathrm{AA}_{142}$.

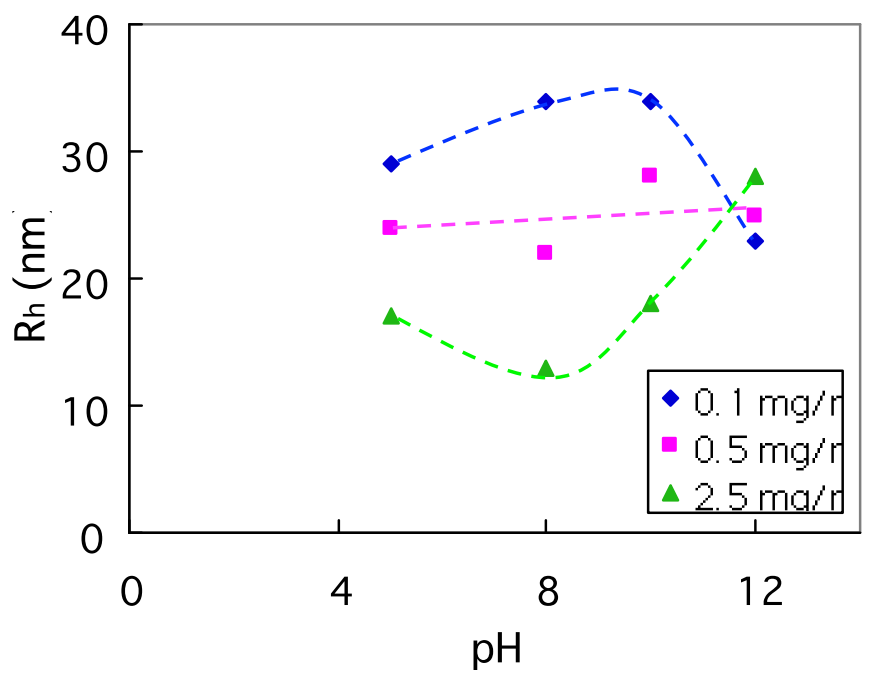

Figure 11. $\mathrm{pH}$ dependence of $\mathrm{R}_{\mathrm{h}}$ of $\mathrm{St}_{44}-b-\mathrm{AA}_{92}$. 

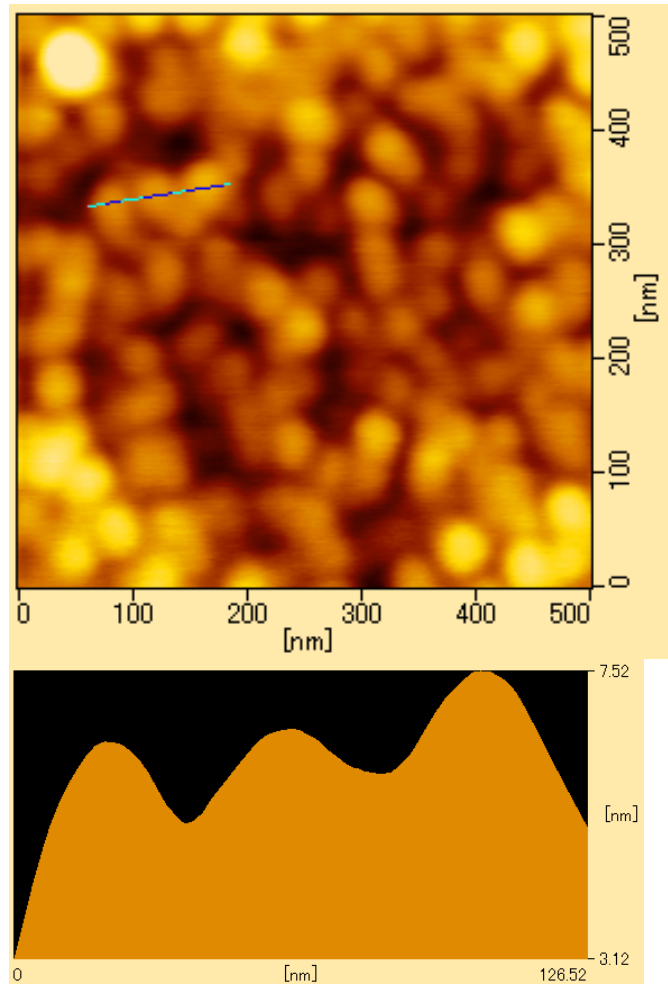

Figure 12. AFM image and line profile of $\mathrm{St}_{44}-b$ $\mathrm{AA}_{92}$.Polymer concentration of the aqueous solution used for sample preparation was $0.1 \mathrm{mg} / \mathrm{ml}$.
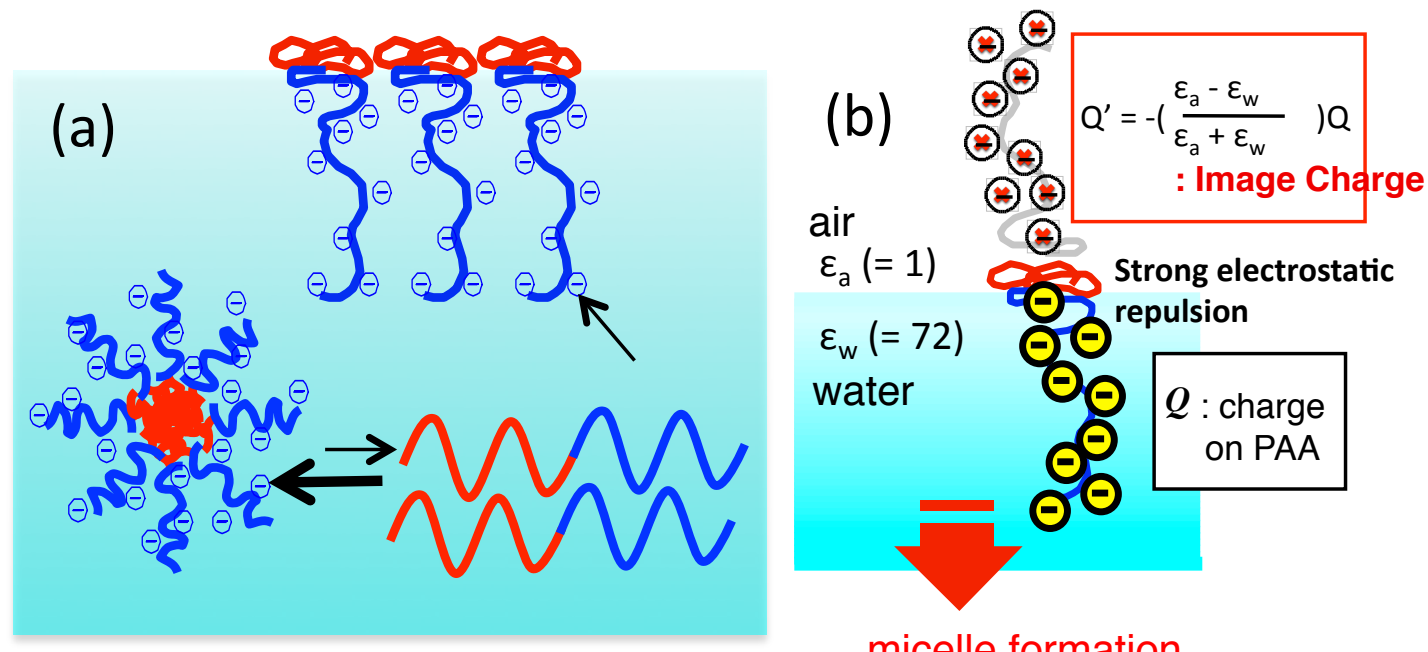

micelle formation

Figure 13. Equilibrium for non-surface active polymers in aqueous solution (a) and schematic representation of image charge effect at the air/water interface (b). Since adsorbed state at the air/water interface is highly destabilized by image charge repulsion and also since polymer micelles in bulk solution is so stable, equilibrium is in favor of micelle formation. 